\title{
ESPACIO Y REFERENCIALIDAD EN LAS FÁBULAS AMERICANAS DE DÁMASO LARRAÑAGA
}

\author{
Space and Referentiality in Dámaso Larrañaga’s Fábulas Americanas
}

\section{RESUMEN}

El spatial turn ha significado para la crítica literaria un retorno al problema del referente, como lo ejemplifica la teorización de Bertrand Westphal acerca de los mundos de la ficción. En este contexto, nos proponemos indagar acerca del vínculo que une a los lugares, los espacios y la ética en las Fábulas Americanas del poeta oriental Dámaso Larrañaga. En primer lugar, analizaremos la tensión en la oda "Al Paraná” de Lavardén a partir de dos ejes (utilidad-ornamento, universal-local), texto al que consideramos representativo de ambas dialécticas en el clasicismo rioplatense. Luego, leeremos varias fábulas de Larrañaga con el objetivo de mostrar la conexión entre el referente axiológico y el referente espacial, que constituyen el eje de la didáctica de las Fábulas americanas. Argumentamos que los poetas del neoclasicismo hispanoamericano emplean la ficción para dotar de sentido a los lugares "nuevos" para la tradición literaria. La referencialidad de los poemas altera de raíz el paradigma clasicista, que pasa a centrarse en el proceso de universalización del valor local, paso previo a la consideración del espacio como vacío o tabula rasa uniforme, puesto al servicio de la producción económica.

\section{UNIVERSUM}

\section{ÁNGEL JOAQUÍN MAISON}

Centro de Estudios de Literatura Comparada "M. T. Maiorana", Facultad de Filosofía y Letras, Universidad Católica Argentina, Argentina.

Correo electrónico:

angeljoaquinmaison@gmail.com

ORCID: 0000-0003-1770-6387

ResearchGate:

Scholar.google: Academia.edu: referencialidad, geocrítica

Palabras claves: neoclasicismo, fábula,

Artículo recibido el 28 de noviembre, 2019. Aceptado el 22 de febrero, 2020.

Web: http://universum.utalca.cl | ISSN: 0716-498X - 0718-2376 


\begin{abstract}
The spatial turn has meant a return to the problem of the referent for literary criticism, as exemplified in Bertrand Westphal's theorizing about fictional worlds. In this context, we set ourselves to the task of analyzing the links between places, spaces and ethics in the Fábulas Americanas written by Uruguayan poet Dámaso Larrañaga. First, we will review tension in Lavardén's ode "Al Paraná", focusing on two axes (utility-ornament, universal-local). We consider his work to be representative of both dialectics in rioplatense neoclassical poetry. Then, we will read three of Larrañaga's fables in order to show the link between the axiological and the spatial referent, which constitute the didactic axis in his Fábulas Americanas. We will argue that Spanish-speaking neoclassical poets in Latin America used fiction to give meaning to places that were "new" to their literary tradition. Referentiality in the poems radically alters the classicist paradigm, as it starts to focus on a process of universalization of local values before spaces can truly be grasped as empty or as a uniform tabula rasa in the service of economic production.
\end{abstract}

Keywords: neoclassicism, fable, referentiality, geocriticism

\title{
INTRODUCCIÓN
}

Este trabajo forma parte de un proyecto más amplio, en el que exploramos la ejemplaridad como parte integral de la poética neoclásica rioplatense, y, en particular, de la producción de los fabulistas de este período. Resulta imposible abordar la noción de ejemplaridad desde un punto de vista exclusivamente literario (si tal cosa fuera posible) o desde la perspectiva del análisis de una sola obra. La clausura semántica tan requerida por los textos de intención didáctica (Suleiman 1993) los hace hostiles a toda investigación que busque aquellos espacios abiertos, de lectura libre, a la vez que los distancia de otras especies literarias. En efecto, las fábulas, junto con los demás relatos ejemplares, son antes un recurso retórico que un verdadero género (en el sentido clásico en el que lo es, por ejemplo, la tragedia). La idea moral precede en el tiempo a los aspectos narrativos, que están en función de ella, pues es el relato el que debe ajustarse a la moraleja y no al revés (Canvat \& Vandendorpe 1996), convirtiéndose en una forma disfrazada de la inducción (Conte 2012). Su clausura semántica está puesta al servicio de una intención práctica: fijar determinada idea, presentarla como evidente, garantizar que sea aceptada. De modo que todo relato cuya función retórica 
sea la de "ejemplo" está anclado necesariamente en el mundo referencial de los interlocutores, característica que, en la fábula, se manifiesta con frecuencia bajo la apariencia de una moraleja, cuya función es reforzar el vínculo entre los comportamientos de personajes ficcionales y los de personas de nuestro mundo. De hecho, el empleo de ficción o de historia es una de las decisiones que toma el orador; de acuerdo con Aristóteles, no hay una diferencia esencial, en cuanto a su valor ejemplar, entre una fábula inventada $a d$ hoc y un ejemplo tomado de acontecimientos históricos o tenidos por tales. La eficacia, por supuesto, puede variar, en tanto el ejemplo propuesto se ajuste o no a las condiciones específicas de una determinada situación comunicativa. Pero no es la veracidad de la narración la que determina la validez del relato ejemplar. En consecuencia, el relato fabulístico, siempre ficcional, entabla con el mundo de la situación comunicativa una relación compleja que será nuestro objeto de análisis. Nos detendremos, sobre todo, en los referentes espaciales, pues son a menudo los más evidentes en los relatos de Dámaso Larrañaga. La especificidad americana es motivo reiterado de la escritura esópica del autor. Lo que convierte a sus fábulas en "americanas" no es el mero trasfondo, sino la centralidad que en ellas ocupan los problemas suscitados por el entorno local. Gracias al espacio, los relatos entran en una sofisticada red semántica, en tanto se conectan con lugares, tiempos y personas cuyo sentido, como en cualquier relato ejemplar, excede al del espacio de la ficción, pues de otra manera serían retóricamente ineficaces.

\section{REFERENCIALIDAD Y ESPACIO}

Bertrand Westphal inserta su propia reflexión acerca de la referencialidad en el contexto de la teoría literaria, al analizar el paso del estructuralismo clásico a las miradas posclásicas que incorporan elementos de la filosofía analítica. La narratología posclásica busca superar, a través de la incorporación de estos paradigmas, la grieta que separa al texto de aquello que no es texto. Westphal señala que "cualquiera sea el nivel de representación, la 
realidad es invariablemente el referente del discurso"1 (Westphal 2007: 87). Así considerada, la ficción no es más que uno entre muchos acercamientos a la realidad, uno que se escuda en una correspondencia limitada o restringida. La literatura es una representación de lo real "infinitamente plástico" (Westphal 2007: 90), cualidad que le extirpamos al tomar una de las posibles posiciones y llamarla "realidad". Hacer geocrítica según los criterios del mencionado teórico supone una revinculación entre el discurso y su referente. Los espacios del texto son cartografías con su propio sistema de significación. No empleamos una metáfora vacía al sostener que los textos fabulísticos construyen una cartografía del comportamiento humano: también allí hay una revinculación entre discurso y referente, y sería fútil cualquier intento de comentar un relato ejemplar sin aludir a un más allá del discurso. El mismo Westphal señala, en efecto, que los operadores deónticos y axiológicos, aquellos que determinan las obligaciones y los valores del mundo del texto, no pueden circunscribirse enteramente a la ficción, a diferencia de otros operadores modales. Dicho de otro modo, una ficción imposible (o, más precisamente, una ficción donde la categoría misma de "posibilidad" se ve alterada) es más fácil de concebir que una ficción en la que los fundamentos de la moral varíen radicalmente, pues los valores morales, según Westphal (2007: 87), "pertenecen al núcleo de toda convención cultural intangible, de la ética". ${ }^{2}$ Como lo demuestra el llamado "puzzle de la resistencia imaginativa" (Gendler 2000), los elementos deónticos y axiológicos de un texto representan horizontes cerrados de lectura. Al lector se le puede informar acerca de valores que, en la ficción, son objetivamente válidos, pero quedan sometidos en última instancia a la evaluación del propio lector. Mientras que un hipotético lector de fantasy o de ficción posmoderna posee un horizonte interpretativo maleable en lo que concierne a las leyes de la física, no parece poder extenderse este juicio a las leyes de la ética o a los principios morales. Resultaría por lo menos curioso que un lector criticara

1 "Whatever the level of representation, reality is invariably the referent of discourse". Las traducciones son nuestras. Para los fragmentos más largos, consignamos el original en nota al pie.

2 "They belong to the core of any intangible cultural convention, to ethics." 
un texto como La metamorfosis por no ajustarse a las leyes de la evolución biológica que rigen en nuestro universo. El narrador puede, potencialmente, adquirir una autoridad absoluta en el plano de los hechos materiales. Parece imposible, por el contrario, presentar con igual grado de certeza valores intangibles. Esta curiosa paradoja no hace más que acercarnos a una conclusión más bien ordinaria: es más fácil para un lector aceptar animales que hablan que un mundo en el que, por ejemplo, todo agente racional tenga la obligación ética de ser cruel con los niños recién nacidos. Westphal, al asociar los operadores deónticos y axiológicos con el problema del referente, nos conduce a conclusiones del todo razonables. Por ejemplo, cuando un lector se pregunta si una ciudad u otro espacio está bien o mal representado en un texto, está haciendo el mismo tipo de juicio que aquel lector que se pregunta si obró bien o mal el héroe novelesco que cuenta con la simpatía del narrador. Es un juicio en el que se involucran los conocimientos acerca del referente, espacial en el primer caso, moral en el segundo. La capacidad de referir excede el hecho de nombrar personas, lugares y hechos materiales.

Dámaso Larrañaga ${ }^{3}$ constituye un caso modelo para estudiar los aspectos referenciales y situados de la poesía neoclásica rioplatense, que a menudo ha sido tenida por parásito peninsular de la realidad autóctona. Contra esta tesis, sugerimos, en cambio, su contrario exacto: la poesía de los neoclásicos rioplatenses solo puede entenderse como una respuesta localizada a problemas del entorno local. Por supuesto, sería improductivo negar todo vínculo con la estética hispánica, pero hacer del inventario de figuras retóricas la totalidad de una escuela equivale ni más ni menos a negar el referente.

3 Dámaso Antonio Larrañaga nació en 1771 en Montevideo. Estudió en el Colegio de San Carlos (Buenos Aires) y continuó su educación en la Universidad de Córdoba. A pesar de su formación bajo maestros tomistas y anticartesianos, Larrañaga se vio notablemente influenciado por las ideas de los ilustrados. Se dedicó, en distintas etapas de su vida, a la historia natural, la política y la literatura. Fue senador y Vicario Apostólico. Falleció en 1848. (Castellanos 1965). 


\section{LA POÉTICA NEOCLÁSICA DEL ESPACIO}

Es necesario situar a Larrañaga en el contexto de una poética que cree en la mejora progresiva de las personas a través de la razón. El impulso educativo es una constante de las publicaciones periódicas en las que aparecen los textos tempranos cuya poética quedaría entronizada en las antologías. El Telégrafo Mercantil" auguraba una "Sociedad Patriótica Literaria y Económica que ha de adelantar las ciencias, las artes, y aquel espíritu filosófico que analiza al hombre, lo inflama, y saca de su soporación, que lo hace diligente, y útil [...] [C]esen aquellas voces bárbaras del Escolasticismo [...] Empiece ya a reglarse nuestra Agricultura" (1 de abril de 1801,3). El rechazo de la filosofía tradicional, premoderna, aquella enseñada por colegios como el San Carlos, al que acudió el mismo Larrañaga, viene acompañado por el deseo de una ciencia empírica que propicie el aprovechamiento de la tierra. La expresión literaria de este sentimiento la hallamos en obras como la oda "Al Paraná" de Manuel José de Lavardén (1998), texto que aparece por primera vez en el citado número del Telégrafo. Su lectura espacial es inevitable si se tiene en cuenta el paratexto que acompaña la edición original bajo la forma de notas al pie, que precisan una serie de datos geográficos e históricos acerca del río y de la región. Como indica Molina en su edición crítica, "las notas incluidas en las versiones no pueden separarse de los versos y tienen un valor ecdótico equivalente" (Molina 1998: 175). "La laguna Apuper, después de Santa Ana, hoy de las Perlas, las ha dado pequeñas en su orilla" (Lavardén 1998: 177): aclaraciones de este tipo fijan el referente, alejando el espectro de la retórica, pues las convenciones estéticas de la oda juegan en contra de su énfasis en la materialidad del espacio. Cuando aparece Océano, en su carro de Nácar, una

4 Fue el primer periódico de Buenos Aires. Se publicó entre abril de 1801 y octubre de 1802. Inspirado en el modelo de la prensa ilustrada europea, divulgó información noticiosa a la par que propagaba saberes "útiles" e ideas políticas de vanguardia. Como sintetizan Pastore y Calvo, el Telégrafo adhiere al principio según el cual "la solución a todos los problemas materiales y espirituales en la sociedad se pone al alcance de la sociedad humana a través de la buena educación" $(2005,447)$. 
nota aclara que "hay en el Paraná multitud de conchas", de modo que podemos extirpar con precisión lo referencial de lo metafórico, el nácar real del carro ficticio. Este proceso es más complejo que una simple puesta en práctica de los principios didácticos de los ilustrados. Constituye una verdadera escisión en el interior del texto, un reconocimiento implícito de que el texto literario es una cartografía, una suerte de mapa verbal, y que entonces, como en todo mapa moderno y científico, conviene trazar un límite claro entre la representación funcional, o seria, y la representación ornamental. Mientras que en el mapa tradicional ese límite, como el vocablo mismo lo indica, se posiciona por fuera del territorio, en el mapa de Lavardén el límite se demarca en el seno de la figura retórica, que aparece "intervenida" por la letra de la correspondiente nota al pie que nos proporciona la información geográfica fidedigna.

El cuidadoso paratexto de Lavardén marca la frontera, garantizando una pulcra discontinuidad entre el lado de lo real y el lado de lo ficticio en las zonas ambiguas. Claro está que las "sencillas ninfas argentinas" (Lavardén 1998: 177) pertenecen al mundo de la mitología, mientras que el "heroico español" (Lavardén 1998: 179) está tomado de la historia reciente. En cambio, necesitan aclaración Ceres (la agricultura) y "la urna de oro" (las minas portuguesas) (Larrañaga, 1998, 181 y 177). Pero las notas del autor no pretenden configurar con nitidez dos compartimentos estancos por mera obsesión clasificatoria. Lo que está en juego en la oda es el saber acerca del Paraná, que debe entenderse en relación a los conocimientos disciplinarios que se promovían desde el Telégrafo Mercantil, el cual, meses después de dar a conocer la oda "Al Paraná", acercaba a sus suscriptores, al mismo tiempo que una fábula compuesta por Domingo de Azcuénaga, unas lecciones de geografía, de la que se afirma "participa de todos los conocimientos humanos" (5 de agosto de 1801, 12). Esa ciencia universal es al mismo tiempo local, pues "colocado el hombre en este globo terráqueo es de su mayor utilidad conocer bien el lugar, o sitio, que le ha cabido en suerte, y para ello debe medirlo, conservarlo, y defenderlo como una propiedad, en que consiste toda su subsistencia [...]" (Telégrafo Mercantil, 5 de agosto de 1801, 12). El periódico tenía como fin conformar "una obra histórica y científica sobre el 
territorio rioplatense" (Ortiz Gambetta 2018: 216), y la oda es parte integral de este plan. No pretendemos sugerir una lectura que convierta al poema en mero efluvio de las ideas ilustradas en América. Como lo demuestran las polifacéticas figuras de la poesía rioplatense durante el período independentista, las letras forman parte de un proceso intelectual más abarcador. Por lo tanto, en la citada oda debemos ver un intento no solo de encauzar este afán geográfico, sino de justificarlo estéticamente. En términos heideggerianos, se trata de fundar aquellos lugares entre los cuales se extiende el espacio, dotándolos de significados híbridos, nacidos del juego entre el imaginario poético y el científico.

Yi-Fu Tuan (2001) adopta la perspectiva de Heidegger al describir la transformación de un bosque en espacio paradójicamente abierto, no porque carezca de obstáculos, sino porque se presenta al ser humano como un espacio ilimitado de posibilidades. Pero el espacio es producido en oposición a un lugar: solo hay espacio en el sentido geográfico cuando la mirada se desplaza más allá del hogar cotidiano. Los espacios son uniformes. Los lugares, creados por la mano del hombre, siempre se nos revelan como internamente estructurados. Una casa tiene habitaciones, cada una dotada de su sentido propio. No ocurre lo mismo con el desierto, el bosque u otros tipos de territorio: por definición, el espacio está "vacío", disponible. Los accidentes naturales cobran una importancia radical, enseñándole al ser humano lo que significa diferenciar un espacio y convertirlo en lugar. Si extendemos este análisis a la oda de Lavardén, comprendemos que el empleo de un vocabulario decorativo (caimanes recamados de oro, urna de oro, ondas de plata, corona de juncos, guirnaldas de amaranto, etc.) transforma las características del espacio en rasgos más fácilmente aprehendidos. Los lugares retóricos de Lavardén son el paso previo a la puesta en literatura de la geografía; en otras palabras, la oda "Al Paraná", en su aspecto lírico, evita cuidadosamente referirse al espacio, o, mejor dicho, se ubica en un estadio previo a su producción en nuestro imaginario. Aquellas características que nosotros atribuiríamos al espacio natural, como la presencia de un metal precioso (un "recurso"), quedan hechas alegoría por la voz lírica. Este procedimiento (para nada novedoso por 
sí mismo) participa de la innegable pulsión cartográfica en los letrados del Telégrafo, generando ese ensamble algo estrafalario de oda neoclásica con notas explicativas. Algunas, como ya señalamos, cumplen un papel aclaratorio. En los casos en los que no hay duda alguna acerca del imaginario en juego, la voz autoral remarca la utilidad de aquello que se describe poéticamente. Por ejemplo, la nota que dice “(j) La Sociedad Económica tenga por objeto, aunque sea único, indagar el nivel de los terrenos, para proporcionar el regadío a nuestros campos" viene a remedar un trío de versos que leen "Extiéndete anchuroso, y tus vertientes / dando socorros (j) a sedientos campos / den idea cabal de tu grandeza” (Lavardén, 1998: 180 - 181). También aparecen destacadas del mismo modo aquellas cosas que el yo lírico (y, por extensión, el Estado mismo) no conoce: "no se sabe adónde llega la riqueza de maderas que poseemos", dice una nota al verso "de incorruptible leño que es don tuyo" (Lavardén 1998: 182). El paratexto pone en evidencia lo que la expresión poética quizás podía disimular.

No buscamos con esta breve lectura reiterar los análisis tradicionales de la oda (por ejemplo, en Barcia, 2001). Una de las carencias de la crítica literaria respecto del corpus neoclásico rioplatense resulta de considerar a estos poetas como productos de una escuela literaria (por otra parte, mal comprendida, como ha señalado en repetidas ocasiones Russell Sebold [1978, 1989]), y no como sus impulsores. El mencionado crítico ve en Lavardén un hombre que "ilustra el programa" (Barcia 2001: 49) a partir de una serie de “distanciamientos y apropiaciones" (Barcia 2001: 50). De hecho, como hemos intentado demostrar, la relación entre el programa geográfico y comercial desarrollado en el Telégrafo y su poesía es problemática. La abstracción que exige el pensamiento científico acerca del territorio no está presente en la oda "Al Paraná", pues el poeta opta por el modelo clásico de apóstrofes y personificaciones. Las polémicas locales que señala Barcia perturban el esquema clasicista. No se trata de un caso aislado: la voz neoclásica del Río de la Plata es radicalmente distinta de la española, porque se ve llamada a utilizar las herramientas tradicionales para defender un proyecto nuevo, $\mathrm{y}$, en consecuencia, aborda sin tapujos el problema del referente. La mediación entre 
los cuatro polos de dos ejes (útil-ornamental y universal-local) constituye la dificultad central a la que se enfrenta el forjador de la oda "Al Paraná". El mismo problema sortea Larrañaga, con notable éxito.

\section{EL ESPACIO EN LAS FÁBULAS DE LARRAÑAGA}

Las Fábulas americanas: en consonancia con los usos, costumbres e historia natural del país, firmadas por "un americano", están fechadas en 1826, pero vieron la luz recién en 1919. La vida de Larrañaga nos permite inferir que se trataba de divertimentos de un hombre que, poco tiempo antes, había quedado ciego. El clérigo se había retirado a su quinta, dedicándose a la cría de gusano de seda, tarea que realizó a la par que dictaba la mencionada obra. No podemos obviar las dos décadas y media que distan entre el primer número del Telégrafo Mercantil y estas Fábulas. Son las décadas de la lucha independentista: el año anterior, la Provincia Oriental se declaraba una más de las Provincias Unidas del Río de la Plata. La oda de Lavardén expresaba con claridad la dependencia política de la colonia, pues sus héroes no dejan de ser españoles; los relatos de los que nos ocuparemos a continuación, en cambio, brotan de una realidad política que ha sufrido una metamorfosis radical. Creo que, sin caer en exageraciones, puede afirmarse que una de las tareas del neoclasicismo hispanoamericano fue demostrar que la pretendida universalidad de las poéticas autorizaba la localización de sus principios. El afán práctico sirvió no solo de pretexto sino de verdadero móvil para dar al espacio local un rol polémico, cuestionador de la doxa predominante. En este sentido, las fábulas de Larrañaga no buscan la confirmación de saberes que ya integran el sentido común, sino la construcción de una doxa nueva, motivada por la experiencia americana.

En la escritura ejemplar tradicional, con eximios representantes que van desde las fábulas de Fedro hasta los exempla de Don Juan Manuel, los referentes se vacían cuidadosamente de todo contenido excepto el deóntico y axiológico. Si consideramos una fábula prototípica, como aquella de "La 
zorra y las uvas", innumerables veces versionada, nada hay en ella que deba ser tenido por real excepto por su mensaje alegórico. ¿Se alimentan de uvas los zorros? ¿Qué motiva la elección de ese fruto? Los zorros, obviamente, no pueden hablar. Este tipo de detalle se presume irrelevante para el público, queda subsumido bajo las convenciones del relato esópico. Como indica Blackham (1985), las imágenes de Esopo son esquemáticas, infinitamente permutables y aplicables. No significa que sean inverosímiles: los comportamientos de los personajes reciben siempre una justificación exacta, al igual que el desenlace de la historia, si bien en la fábula, como en todo relato de raigambre tradicional, las motivaciones psicológicas no son motivos perdurables en el tiempo (Vandendorpe 1991). Los arquetipos se eligen para aislar determinadas características del referente. Por ejemplo, el león es un animal fuerte, mientras que el ratón es débil. Las fábulas no nos dicen mucho que no sepamos acerca de los animales que las protagonizan; de hecho, apelan al estereotipo para ganar eficacia. En cambio, las fábulas de Larrañaga son a menudo un comentario acerca de los sujetos que las protagonizan. Su referente es parte de la narración: no están construidas para su universalización como esquemas morales, sino para divulgar una valoración específica acerca de personas, hechos y lugares americanos.

En la fábula "El zorro y la zorra", el macho es astuto, competente en las tareas zorrunas, y originario de Europa; su pareja, en cambio, es dócil, torpe y americana. La cría es una incógnita que se resuelve en favor del padre: "en menos de un año / nada se escapaba: / pollos, gallipavos, / conejos y patos", con una moraleja que estimula el mestizaje: "Al cruzar las castas / aún de los humanos / que éstas se mejoran / es esto bien claro" (Larrañaga 1919: 39-40). Por un lado, opera aquí la archiconocida secuencia narrativa que Bremond llamó "ejemplar": a una acción buena sigue un resultado positivo (Bremond, Le Goff \& Schmitt 1996). Como consecuencia de la cruza entre el zorro europeo y la zorra americana, la cría tiene las cualidades óptimas de sus padres. Por otro lado, se necesita una sinécdoque según la cual podemos decir de los animales como conjunto (y, por lo tanto, del ser humano en particular) lo que decimos del zorro como parte. Es notable que no se trate de una alegoría 
sin más. No estamos ante un mecanismo de pura correspondencia formal. Larrañaga recurre a una sinécdoque en la cual las personas integran el mismo todo que los zorros (el conjunto de los animales). En la fábula tradicional hay un dominio de partida, el mundo animal, y un dominio de llegada, el mundo de los seres humanos, y el tránsito entre los dos es vehiculado por una suerte de relectura de la conducta animal en términos voluntaristas o morales. Las observaciones zoológicas, reales o inventadas, se convierten en imágenes de vicios y virtudes. Tal observación no aplica a nuestra fábula, que se acerca, en cambio, a un modelo de hipótesis y deducción fundado en parecidos verificables entre ambos dominios. Los versos iniciales anticipan el valor casi científico de su moraleja, pues nos informan que "A la Zoología / un americano, / por útil recreo, / era dedicado" (Larrañaga 1919: 37). Como el mismo Larrañaga, el americano de la fábula es un naturalista, pero también es imagen del lector, si suponemos que esas fábulas pueden leerse "por útil recreo".

El tránsito Europa-América, que tiene como consecuencia el mestizaje ensalzado por Larrañaga, trae a la ficción esópica el problema del referente. La fábula demuestra que los mestizos son sanos a partir de un ejemplo que cualquier naturalista daría por válido, y de allí deduce la moraleja. El contenido científico de la fábula parece venir exigido por el carácter novedoso de los espacios americanos. Antes que nuevas analogías, el continente exige nuevas evidencias, la producción simbólica de nuevos lugares. Para construir una fábula que comentara acerca del vínculo entre europeos y americanos, era necesario que en ella hubiera un predominio absoluto del referente, pues los lugares siempre están determinados por la experiencia y el uso, y no pueden fundarse sobre sistemas abstractos. Al igual que en Lavardén, el texto pretende confrontar al lector con pruebas materiales de la diferencia. Para ello, recurre a una convención clásica, los animales parlantes que tienen un acceso intuitivo a saberes tradicionales, pero la modifica, pues esos saberes ya no están presupuestos en la construcción de una trama, sino que esta pone en evidencia un hecho de la zoología y, sin trasladarse del todo al plano alegórico, lo hace evidente también para las sociedades humanas. Este modo 
de proceder, de acuerdo con nuestro esbozo teórico del principio, llevaría a las fábulas de Larrañaga a establecerse casi por completo en nuestro mundo. Salvo la anécdota de los zorros que hablan, obviamente inventada, todo lo demás mantiene una distancia mínima con las verdades de la realidad en la que el autor creía.

La fábula acerca de Neptuno y el Río de la Plata emplea un recurso similar. En ella, Neptuno le reclama al Argentino la plata que le da su nombre, y lo acusa de carecer de riquezas. Pero la ninfa del Río de la Plata replica que los metales preciosos son meras representaciones de la riqueza, que está en los campos y el ganado. Ofrece como contraejemplo el siguiente caso: "Ni de oro ni de plata tiene minas, / Neptuno, tu anglo floreciente imperio" (Larrañaga 1919, 29). Conviven aquí dos intenciones didácticas. Primero, el texto intenta dar respuesta a la pregunta sobre la verdadera esencia de la riqueza material. La segunda, en cambio, depende por completo del referente, y se trata de una aseveración sobre economía. ¿Es el Río de la Plata tan rico como su nombre? En cuanto a la ontología de su objeto didáctico, esta fábula es mixta, y ligeramente más compleja que la anterior, pues antes de emitir un juicio sobre los referentes espaciales, utiliza el debate alegórico entre las ninfas para establecer una definición clara del término "riqueza". La comparación con la oda "Al Paraná" resulta fructífera. Larrañaga, como Lavardén, separa cuidadosamente dos mundos, el del placer de los sentidos y el de la racionalidad económica. Neptuno aparece "En su rica carroza muy brillante / de nácar con aljófar guarnecida" (Larrañaga 1919: 28), pero, al fin y al cabo, comprende las razones de la ninfa argentina acerca del valor agrícola del desagradable lodo. El nácar, que en la oda de Lavardén pertenecía al carro del Paraná, aquí es propiedad de Neptuno. Pertenece al grupo de las convenciones empleadas en la personificación de un cuerpo de agua. Esta feliz coincidencia entre imagen poética y realidad material (pues el Paraná, según Lavardén, cuenta con este recurso) es la que motiva como por reflejo su separación en el texto aparecido en el Telégrafo Mercantil. La tensión entre materia económica y ornato literario bien puede verse como una de las constantes en la poética neoclásica rioplatense. La belleza apreciada por estos poetas no es principalmente belleza 
sino valor, y, cuando hubo faltado, siempre pudo sustituirse con el artificio del poeta. La bella ninfa que canta al potencial productivo del río, sarmientina avant la lettre, es un perfecta síntesis de esa dialéctica.

Como el poeta, instruye Neptuno: "Haz que tus hijos sepan tal doctrina” (Larrañaga 1919: 29). Este mandato generacional anticipa, a su manera, las obsesiones productivas de hombres como Sarmiento, que vieron en los ríos argentinos una fuente de riqueza desaprovechada como resultado de la novedad geográfica: "Todos los sistemas conocidos de distribución de la tierra fallan en su aplicación a las islas del Delta del Paraná" (Sarmiento, 1899: 42). Destacamos dos diferencias: el referente, pues se trata de otro río, y la transformación del problema del territorio y su riqueza en una cuestión de agrimensura. Los tópicos respecto de la riqueza del Paraná y el Río de la Plata ya habían sido absorbidos por el sentido común.

Por otra parte, la fábula titulada "Manco-Capac, inca" exalta la justicia de un imperio "sabio, dulce, humano" (Larrañaga 1919: 32), contrapuesto a la "locura" del inca que "descendido del cielo y del Sol hijo / fingió ser, para hacerse soberano". (Larrañaga 1919: 32). El procedimiento ejemplar es cuanto menos curioso, pues el único contenido general y abstracto que de ella podemos extraer es la mera posibilidad de que coexistan el paganismo y el buen gobierno, la civilización y la barbarie. El Inca es llamado "bárbaro" en el primer verso del poema, pero luego, en el anteúltimo, la acusación se invierte, y la voz narradora sugiere que quizá sea más bárbaro quien niega el buen gobierno de Manco-Capac. La ejemplaridad aparece problematizada por la "rugosidad" de un referente que no tiene la perfección del modelo pulido por el tiempo. Si entendemos lo local como contrapuesto al menos en parte a lo universal, este texto termina por convertirse en un modelo de narrativa fabulística no ejemplar, sino polémica. La generalización importa poco. El poema entroniza un referente nuevo (una vez más, solo desde el punto de vista de la tradición literaria), que lleva el rótulo de "peruano", es decir, que está situado en el territorio americano. Una y otra vez en la fabulística de Larrañaga, cuando el referente irrumpe en la estructura prolija de sus relatos, lo hace porque es necesario para pensar el territorio y la localidad, y la posibilidad 
de una escuela poética autóctona. La espacialidad altera el funcionamiento de las técnicas discursivas propias de la fábula, y pone el texto al servicio de una caracterización positiva de América, una ética de la autoctonía. En esta línea, podemos hablar de un tránsito retórico: la experiencia de lo local específico transmuta el ejercicio didáctico, que siempre apunta a lo universal, y lo convierte en una retórica de la experiencia local. Los mundos axiológicos y deónticos quedan, como aventurábamos al principio, íntimamente conectados con otros horizontes referenciales de lectura, como los lugares. Los preceptos de la fábula, como los espacios, son puntos de anclaje en el proceso de interpretación, o, para retomar el término introducido anteriormente, son puntos de clausura, en tanto pueden corroborarse las significaciones del texto con el referente al que aluden.

Los textos que hemos estudiado a lo largo de este artículo contradicen algunas de las premisas largamente sostenidas según las cuales los poetas neoclásicos fueron simples "escueleros" que llevaron a cabo una poesía mecánica. El proceso de referencialización de las convenciones añejas es, en realidad, una poética legítima en sí misma, que logra extremar la cercanía entre el texto y su referente. La intención utilitaria, gracias a los accidentes de la historia y de la geografía, se vuelve en América verdadero motor artístico, pues exige la incorporación de material autóctono a formas líricas y narrativas que son reacias a la novedad. Como hemos procurado argumentar, la atención puesta en el espacio por los autores que hemos seleccionado revela contactos y continuidades con sus sucesores (aunque no herederos) literarios, a pesar del rechazo taxativo que sufriría el clasicismo durante la siguiente generación. Sigue siendo un objetivo a cumplir un estudio exhaustivo no solo de los fabulistas del período, sino también una reexaminación de la prosa y el verso. Si no hemos heredado su gusto, recibimos, al menos, los lugares que habitaron: la crítica espacial tiene, así, el potencial de renovar nuestra mirada. 


\section{REFERENCIAS}

Barcia, Pedro Luis. "Las letras rioplatenses en el período de la Ilustración: Juan Baltasar Maciel y el conflicto de dos sistemas literarios". Humanidades: revista de la Universidad de Montevideo 1/1 (2001): 41-60.

Blackham, Harold John. The Fable as Literature. Londres: The Athlone Press, 1985.

Bremond, Claude, Le Goff, Jacques. \& Schmitt, Jean-Claude. L'"exemplum". Burnhout: Brepols, 1996.

Canvat, Karl \& Vandendorpe, Christian. "La fable comme genre: essai de construction sémiotique”. Pratiques 91 (1996): 27-56.

Castellanos, Alfredo R. "Prólogo", en Dámaso Antonio Larrañaga. Selección de escritos. Montevideo: Ministerio de Instrucción Pública y Previsión Social, 1965.

Conte, Filippo. "Studi sull'exemplum". Le forme e la storia VI/1 (2013): 277292.

Ortiz Gambetta, Eugenia. "Textos permeables: archivo colonial, prensa y literatura en el Río de la Plata”. Universum 33/1. (2018): 212-239.

Larrañaga, Dámaso Antonio. Fábulas americanas. Montevideo: Imprenta de Dornaleche Hermanos, 1919.

Lavardén, Manuel José de. "Al Paraná", en Molina, Hebe Beatriz. "Edición crítica de la oda 'Al Paraná' de Lavardén”. Incipit XVIII (1998): 159186.

Molina, Hebe Beatriz. "Edición crítica de la oda 'Al Paraná' de Lavardén". Incipit XVIII (1998): 159-186.

Pastore, Rodolfo y Calvo, Nancy. "Ilustración y economía en el primer periódico impreso del Virreinato del Río de la Plata: el Telégrafo Mercantil (1801-1802)". Bulletin Hispanique 2 (2005): 433-462.

Sarmiento, Domingo Faustino. Obras. Tomo XXVI. El camino del Lacio. Buenos Aires: Imprenta y Litografía "Mariano Moreno", 1899. 
Suleiman, Susan Rubin. Authoritarian Fictions: The Ideological Novel as a Literary Genre. Nueva York: Columbia University Press, 1993.

Telégrafo Mercantil. Buenos Aires, 1 de abril de 1801.

Telégrafo Mercantil. Buenos Aires, 5 de agosto de 1801.

Tuan, Yi-Fu. Space and Place: The Perspective of Experience. Minneapolis: University of Minnesota Press, 2001.

Vandendorpe, Christian. "De la fable au fait divers". Les cahiers de recherche du CIADEST 10 (1991). Consultado digitalmente en: http:// pascalfroissart.online.fr/3-cache/1991-vandendorpe.pdf

Westphal, Bertrand. Geocriticism. Nueva York: Palgrave Macmillan, 2007.

Sebold, Rusell. El señorito mimado. La señorita malcriada. Madrid: Clásicos Castalia, 1978.

- El rapto de la mente. Poética y poesía dieciochescas. Barcelona: Anthropos, 1989. 